\section{Plants and $\mathrm{CO}_{2}$ : A Quick and Easy Laboratory Exercise}

\author{
Thomas E. Marler and \\ Haluk M. Discekici
}

Additional index words. Lycopersicon esculentum, photosynthesis, adventitious roots

Summary. A laboratory exercise is outlined in which breath is used as the source for elevating $\mathrm{CO}_{2}$. Single-plant enclosures are constructed by placing containers with stem cuttings within clear bags for maintaining high humidity during root initiation. These enclosures provide a restricted atmosphere in which elevated $\mathrm{CO}_{2}$ is adequately confined. The materials are inexpensive and readily available. The procedure is rapid, with results obtained in as few as 7 days. The increase in canopy and/or root growth as a result of elevated $\mathrm{CO}_{2}$ may be observed visually by younger audiences, or may be measured and analyzed in a manner dependent on the age group. The exercise generates an abundance of discussion and may be used to lead into many lectures on plant physiology, horticultural crop production, or global concepts of $\mathrm{CO}_{2}$ and the plant kingdom.

A tmospheric $\mathrm{C} \mathrm{O}_{2}$ concentration is suboptimal for obtaining maximum photosynthesis for most plants (Bonner, 1962). Increasing $\mathrm{CO}_{2}$ concentration artificially is problematic in crop production for two reasons. First, a relatively inexpensive source of $\mathrm{CO}_{2}$ generation is needed. Second, an enclosure to restrict loss of generated $\mathrm{CO}_{2}$ is required to maintain the elevated $\mathrm{CO}_{2}$ around the crop and to keep the procedure from being wasteful and expensive. The first requirement is met

\footnotetext{
College of Agriculture and Life Sciences, University of Guam, Mangilao, Guam 96923.

The cost o publishing this paper was defrayed in part by the payment of page charges. Under postal regulations, this paper therefore must he hereby marked advertise ment solely to indicate this fact.
}

easily in crop production with commercially available $\mathrm{CO}_{2}$ generators. The second requirement is by far the greatest problem, as ventilation is typically needed for maintaining adequate cooling in enclosed growing structures.

These same problems plague any instructor whose desire is to demonstrate the influence of elevated $\mathrm{CO}_{2}$ on plant growth. However, propagation of semihardwood, softwood, or herbaceous stem cuttings requires some form of minimizing the loss of tissue water content, since the transpiring surface is intact throughout the props: gation period. This is accomplished most often commercially with intermittent mist systems. Alternatively, small inexpensive units for maintaining high humidity are constructed easily with a polyethylene bag placed over the pot and stem cuttings (Hartmann et al. 1990). We have found that this unit provides an adequate confined atmosphere in which to elevate $\mathrm{CO}_{2}$.

We outline a classroom exercise, appropriate for all age groups, for demonstration of the influence of elevated $\mathrm{CO}_{2}$ on plant growth. The plant material is stem cuttings, and the responses measured are stem and root growth. The required enclosure is a single unit plastic ziploc bag for maintaining high humidity to ensure adequate rooting of stem/leaf cuttings. Members of the targeted audience use their breath to increase $\mathrm{CO}_{2}$ in the plastic bag.

\section{Procedures}

Fifly-six 625-ml containers were filled with washed silica sand and saturated with a complete nutrient solution (Excel, Grace-Sierra, Milpitas, Calif.) on 15 Mar. 1995. Stem cuttings of 'N65' tomato (Lycopersicon esculentum Mill. ) were made from 3week-old seedlings. We selected tomato for the exercise, because stem cuttings root easily and rapidly, and because of the long history (Thomas and Hill, 1949 ) and current widespread practice (Poorter, 1993) offertilizing this species with $\mathrm{CO}_{2}$ under protected commercial production. The cuttings were standardized to $13.3 \mathrm{~cm}$ in length, and fresh weights were measured. The basal $1.5 \mathrm{~cm}$ of each cutting was dipped in $0.1 \%$ indole-3-butyric acid (in powder) to enhance adventitious root formation and inserted in the silica sand, one per container. The containers then were placed individually in 3.78-liter clear, ziploc bags. The bags were placed on a concrete bench in a shadehouse (about 10\% sunlight transmission, maximum photosynthetic photon flux was 230 to 240 $\left.\mu \mathrm{mol} \cdot \mathrm{m}^{-2} \cdot \mathrm{s}^{-1}\right)$. This level of shade was used because direct sunlight can cause over-heating within these propagation units (Hartmann et al., 1990).

Ten additional cuttings were used to establish the relationship between flesh and dry mass (to a constant weight at 70C) for these cuttings. Dry weight was $9.92 \% \pm 0.32 \%$ of fresh weight, and this figure was used to estimate the initial dry weight of each cutting from the fresh weight. Initial root dry weight was zero.

Four treatments were administered. The control treatment consisted of filling the bag with ambient air using a small bicycle tire pump. Elevated $\mathrm{CO}_{2}$ was administered to the remaining units by exhaling into them in order to completely displace existing ambient gases prior to closure of the bags. The three elevated $\mathrm{CO}_{2}$ treatments were based on frequency of recharging with breath. One group received the exhaling treatment only one time on 15 Mar., the second group received the treatment weekly, and the third group received the treatment three times weekly. There were seven cuttings in each of the four treatments, arranged randomly within each of two blocks. Temperature ranged from 26 to $33 \mathrm{C}$ for the duration of the study.

One block was selected at random on day 7 , and the plants were removed from the plastic bags. Base of cuttings and roots were cleaned by gentle washing. Roots were removed from the stem with a razor blade. Canopy and roots were dried to a constant weight at 70C. Plants in the second block were removed and prepared in the same manner on day 14 .

Canopy dryweight did not change for the duration of the study for cuttings in ambient air or in propagation units receiving elevated $\mathrm{CO}_{2}$ from breath only once or weekly. However, canopy dry weight of the cuttings receiving elevated $\mathrm{CO}_{2}$ from breath three times weekly increased $6 \mathrm{mg}$ per day during the 2-week period.

Root dry weight increased with time in a linear fashion for all four treatments. Root dry weight on cuttings receiving elevated $\mathrm{CO}_{2}$ only once was not different at day 7 to that of cuttings receiving elevated $\mathrm{CO}_{2}$ weekly. However, root dry weight of the cut- 


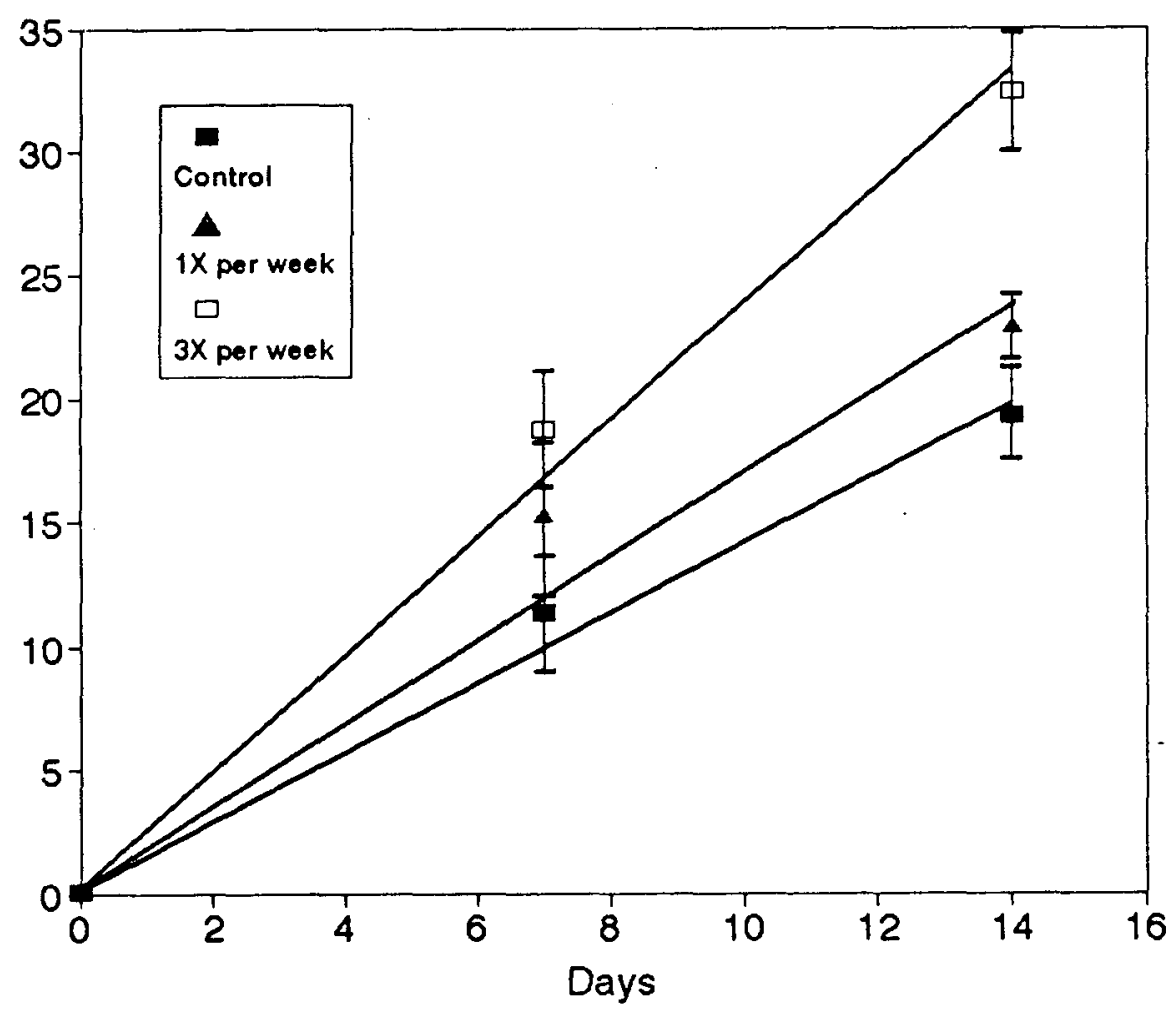

on the overall carbon budget during assimilation and maintenance of organs in a growing plant.

Horticultural crop production. The practical horticultural application of $\mathrm{CO}_{2}$ fertilization is another subject easily made relevant to a horticultural production class following this exercise. Indeed, most $\mathrm{CO}_{2}$ enrichment research over the last few decades has centered on the direct stimulation of crop production (e.g., Cure and Acock, 1986). Efficient use of water resources has become of utmost importance in crop production in most geographic regions, and elevated atmospheric $\mathrm{CO}_{2}$ limits transpiration via partial stomatal closure concurrent with the increase of photosynthesis (Kozlowskietal.,1991).As a result, water use efficiency is enhanced with elevated atmospheric $\mathrm{CO}_{2}$, and this exercise

Fig. 1. Dry weight of root tissue on tomato cuttings as influenced by time and elevating $\mathrm{CO}_{2}$ within the propagation units with breath one or three times per week. Response curves are described by the following equations: $y=0.65+1.37 x, r^{2}=0.59^{* *}$ (control); $y=1.50+1.63 x, r^{2}=0.52^{*}$ (one time per week); $y=0.91+2.31 x, r^{2}=0.63^{* *}$ (three times per week). Data points are mean \pm standard error. $n=7$.

tings receiving elevated $\mathrm{CO}_{2}$ once was not different from that of the control cuttings by day 14 . Data for the other three treatments were plotted as a function of time, and the slope was lowest for the ambient plants, highest for the plants receiving $\mathrm{CO}_{2}$ three times weekly, and in between these extremes for the plants receiving $\mathrm{CO}_{2}$ weekly (Fig. 1).

The increase in biomass for each $\mathrm{CO}_{2}$ enrichment treatment as compared with the ambient treatment was determined on a relative enhancement scale by calculating the ratio of total biomass increase to absolute biomass of ambient plants [i.e. (elevated - ambient)/ambient]. At day 7, plants receiving $\mathrm{CO}_{2}$ enrichment once weekly exhibited a 38\% enhancement, and plants receiving $\mathrm{CO}_{2}$ enrichment three times weekly exhibited a $64 \%$ enhancement of root growth as compared with the control plants. A similar pattern was evident at day 14 , with $18 \%$ or $67 \%$ enhancement over the control plants for the one time or three times weekly $\mathrm{CO}_{2}$ enrichment treatments, respectively.

\section{Classroom discussion}

Plant physiology. This laboratory exercise generates an abundance of questions and discussion. Many plant physiology lectures maybe built around the results. Certainly the direct stimulation of photosynthesis (Cure and Acock, 1986) by elevated $\mathrm{CO}_{2}$ which is required for an increase in dry matter of this magnitude provides an easy transition from the exercise into a general discussion of photosynthesis. In addition, elevated $\mathrm{CO}_{2}$ increases the rate of carboxylation and inhibits oxygenase activity of rubisco (Kozlowski et al., 1991), so a transition into a discussion of photorespiration is also feasible. This discussion may further evolve into a comparison of $\mathrm{C}_{3}$ and $\mathrm{C}_{4}$ characteristics, as the inhibition of photorespiration by elevated $\mathrm{CO}_{2}$ provides a greater relative increase in productivity of $\mathrm{C}_{3}$ plants (Allen, 1979). Increased $\mathrm{CO}_{2}$ also inhibits plant respiratory processes directly in addition to photorespiration (Ziska and Bunce, 1994). The exercise thus may be used to introduce a lecture on respiration or may lead into this or a similar discussion.

Plant responses global $\mathrm{CO}_{2}$ increases. The response of plants to global increases in atmospheric $\mathrm{CO}_{2}$ also may be discussed in detail, with the results of the exercise used as evidence. The $\mathrm{CO}_{2}$ concentration in the atmosphere during the 1980s is expected to double during the next 50 to 100 years (Gates, 1983). Continued increase in global atmospheric $\mathrm{CO}_{2}$ to $400 \mu \mathrm{l} \cdot$ liter $^{-1}$ should increase photosynthesis of $\mathrm{C}_{3}$ plants as a whole about $20 \%$ above current values, as long as all other factors remain nonlimiting (Allen, 1979). The major factor that may become limiting to photosynthesis in some locations is temperature. A doubling of the current atmospheric $\mathrm{CO}_{2}$ concentration may lead to more than a $4 \mathrm{C}$ increase in global surface temperature (Kerr, 1986). While many of the predictions of global climate changes remain speculative, a lively discussion on the subject is certain to evolve from this laboratory exercise. For instance, will the differential growth response among species to elevated $\mathrm{CO}_{2}$ lead to a change in natural succession within some habitats?

Role of plants in atmospheric $\mathrm{CO}_{2}$ changes. Plants are an important component in the carbon cycle through mitigation of the global atmospheric 
$\mathrm{CO}_{2}$ increases caused by mankind. The influence of the plant kingdom in global carbon balance is dependent not only on carbon fixation, but also on $\mathrm{CO}_{2}$ efflux. A small change in $\mathrm{CO}_{2}$ efflux from terrestrial ecosystems could have a large influence on global carbon balance (Woodwell, 1988). Since loss be as high as $-50 \%$ of the carbon fixed during photosynthesis (Amthor, 1989), the direct inhibition of respiratory processes by elevated $\mathrm{CO}_{2}$ may be of global importance. Elevated atmospheric $\mathrm{CO}_{2}$ concentration also may affect the hydrologic cycle, as stomatal conductance to $\mathrm{H}_{2} \mathrm{O}$ for a range of crop species decreased an average of about $35 \%$ when they were grown at about twice the current atmospheric $\mathrm{CO}_{2}$ concentration (Cure and Acock, 1986).

\section{Suggested methods}

The materials required to conduct this exercise are readily available and inexpensive. Students may even be asked to bring the required materials from home. This exercise is simple, and applying the $\mathrm{CO}_{2}$ enrichment in this manner can be performed easily

Fig. 2. Tomato cuttings on the day of propagation (left) and on day 10 for cuttings with ambient air within single enclosed polyethylene propagation units (middle) and for cuttings with elevated $\mathrm{CO}_{2}$ from breatb within the propagation units (right). of carbon via respiratory processes may

with the youngest school children. The results are obtained quickly, in as little as 7 days with proper management. The methods of data collection can be tailored to age of the audience. While the mathematical calculations are beyond the scope of easy comprehension, a visual documentation of the plant response (Fig. 2) is adequate for el ementary age audiences, and certainly provides a graphic verification of the response. Easily visualized is the adventitious root formation accompanied by little or no canopy growth for 10-dayold cuttings in ambient conditions, and a stimulation of canopy growth and root growth for 10-day-old cuttings receiving elevated $\mathrm{CO}_{2}$. Middle school-age audiences may generate a simple data set by visually ranking the degree of rooting for each cutting. The exercise is appropriate for high school or university level audiences in the form of data collection and presentation we have described herein.

The list of appropriate model species for use in this exercise is restricted only by capability of developing adventitious roots on stem cuttings. Species with rapid rooting response may be most appropriate for working with younger school-age children, since a long experimental period may become discouraging for this age group. T.E. Marler has conducted this exercise successfully with upper division university students using tomato, wandering jew (Tradescantia fluminensis Veil.) and

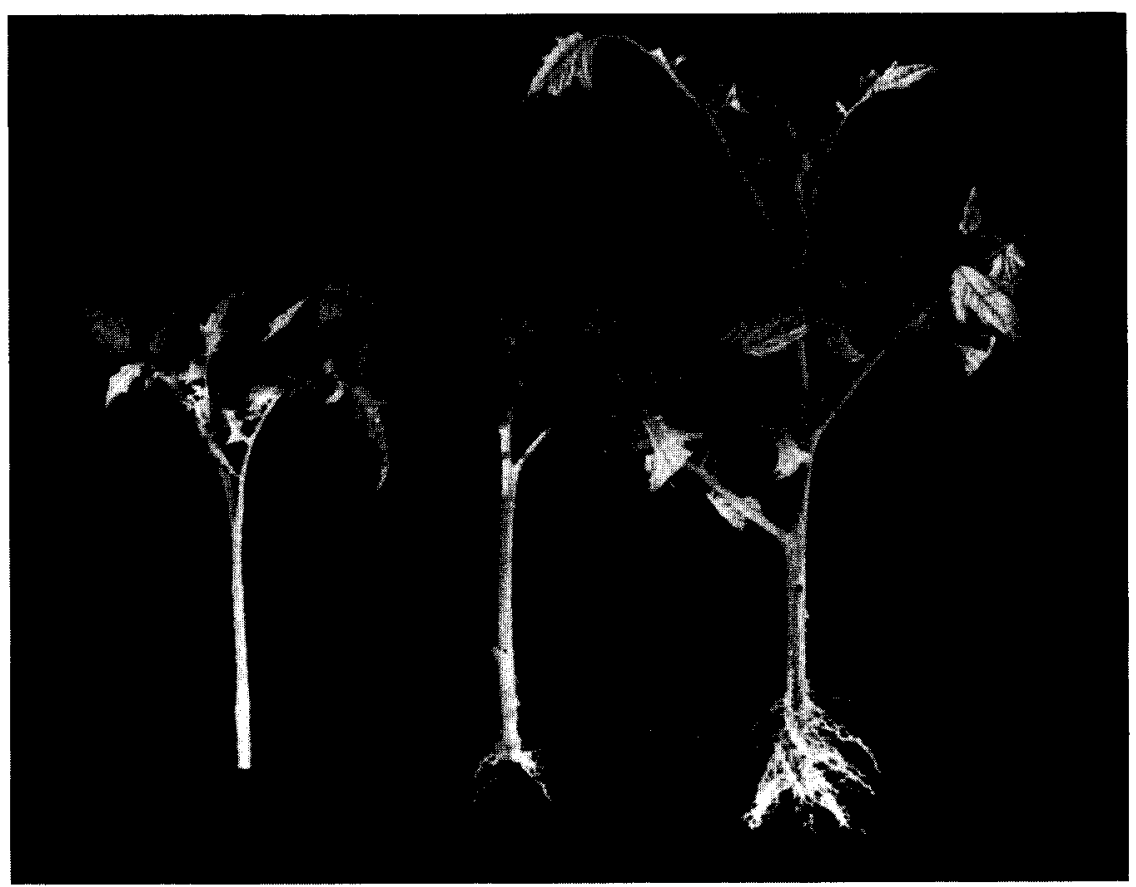

weeping willow (Salix babylonica L.) cuttings. The most rapid response of the species used to date was obtained from Ipomoea aquatica Forsk. cuttings. This was obtained while T.E.M. was teaching an in-service training for public high school science teachers. Elevating $\mathrm{CO}_{2}$ with breath led to a 2fold increase in canopy growth, and a 3 -fold increase in root growth in 7 days.

Leaves on tomato cuttings (and those of other species) obtained from full sun plants may become chlorotic when transferred to the low light required for temperature control in the propagation units. A potential method to minimize this problem is to begin with shade-adapted stock plants by providing a period of shade before taking the cuttings.

The proposed methods may be modified in any number of ways. For instance, a dose-response curve may be generated using bags with a standard volume. The entire population of units may be fully charged with a bicycle pump to ensure the entire volume is at ambient concentration, then ambient air may be diluted with one breath, two breaths, and so on until the greatest $\mathrm{CO}_{2}$ dose consists of completely displacing ambient air. Fully replacing ambient air with breath should result in $\mathrm{CO}_{2}$ concentration of 1350 to $1450 \mu \mathrm{l} \cdot$ liter $^{-1}$. The accuracy of this procedure is dependent on high-quality bags with no leaks. We have found that generic brand bags may lose volume rapidly, indicating loss of gases within the enclosed atmosphere. The potential to retain the prescribed dosage may be enhanced by purging and repeating the procedure fairly often.

\section{Conclusions}

We have outlined an exercise to teach about the effects of $\mathrm{CO}_{2} \mathrm{O}$ n plants with methods that are simple enough for elementary-age audiences. The magnitude and level of difficulty of data collection maybe tailored easily to any age group. The exercise may lead into many basic lectures on plant physiology. In addition, the exercise may be used to teach concepts of $\mathrm{CO}_{2}$ fertilization in crop production, the response of plants to global atmospheric $\mathrm{CO}_{2}$ increases, and the role of the plant kingdom in ameliorating the global increase in atmospheric $\mathrm{CO}_{2}$. 


\section{Literature Cited}

Amthor, J.S. 1989. Respiration and crop productivity. Springer-Verlag, New York.

Allen, L.H. 1979. Potentials for carbon dioxide enrichment, p. 500-519. In: B.J. Barfield and J.F. Gerber (eds. ). Modification of the aerial environment of crops. Amer. Soc. Agr. Eng., St. Joseph, Mich.

Bonner, J. 1962. The upper limit of crop yield. Science 137:1 1-15.

Cure, J.D. and B. Acock. 1986. Crop response to carbon dioxide doubling: A literature survey. Agr. For. Meteorol. 38:127145.
Gates, D.M. 1983. An overview, p. 7-20. In: E.R. Lemon (cd.). $\mathrm{CO}_{2}$ and plants. Westview Press, Boulder, Colo.

Hartmann, H. T., D.E. Kester and F. T. Davies, Jr. 1990. Plant propagation: principles and practices. 5th ed. Prentice Hall, Englewood Cliffs, N.J.

Kerr, R.A. 1986. Greenhouse warming still coming. Science 232:573-575.

Kozlowski, T.T., P.J Kramer, and S.G. Pallardy. 1991. The physiological ecology of woody plants. Academic Press, San Diego.

Poorter, H. 1993. Interspecific variation in the growth response of plants to an el- evated ambient $\mathrm{CO}_{2}$ concentration. Vegetation 104/105:77-97.

Thomas, M.D. and G.R. Hill. 1949. Photosynthesis under field conditions, p. 19-52. In: J. Franck and W.E. Loomis (eds.) Photosynthesis in plants. Iowa State College Press, Ames.

Ziska, L.H. and J.A. Bunce. 1994. Direct and indirect inhibition of single leaf respiration by elevated $\mathrm{CO}_{2}$ concentrations: interaction with temperature. Physiol. Plant. 90:130-138.

Woodwell, G.M. 1988. The global carbon cycle: Letter to Science. Science 241:17361737. 